\title{
Physicians pressed to play nice
}

Published at www.cmaj.ca on Jan. 22

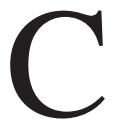
anadian public health officials and provincial medical associations faced sustained criticism at a health care summit for failing to more widely implement collaborative approaches to primary health care delivery.

"Public health has become overlyspecialized and removed from primary care," Vivek Goel, president and CEO of the Ontario Agency for Health Protection and Promotion, told the Canadian Institutes of Health Research (CIHR) Primary Care Summit on Jan. 19. "What we now really want to get to are primary health care teams working with communities."

Noting that well-established teambased approaches to primary health care, such as Sault Ste Marie's Group Health Association Clinic, were built in the face of "fighting all the way" from government health authorities, Goel said Canada suffers from "too many pilot projects" experimenting with team-based approaches and not enough commitment to permanently integrating them into provincial health systems.

Even in Ontario's Chronic Disease Prevention and Management Framework — which was aimed at delivering health care through teams comprised of doctors, pharmacists, psychologists, nurses and other health workers - the primacy of physicians "is still overemphasized," Goel added.

Ten years after the federal government committed $\$ 800$ million to a Primary Health Care Transition Fund, and seven years after Canada's First Ministers agreed that at least $50 \%$ of Canadians should have access to a multidisciplinary primary health care team 24 hours a day, seven days a week by 2011 , progress remains painfully slow. As of 2008, 4.1 million Canadians did not even have a regular family doctor.

In Saskatchewan, the province with the highest level of success in creating

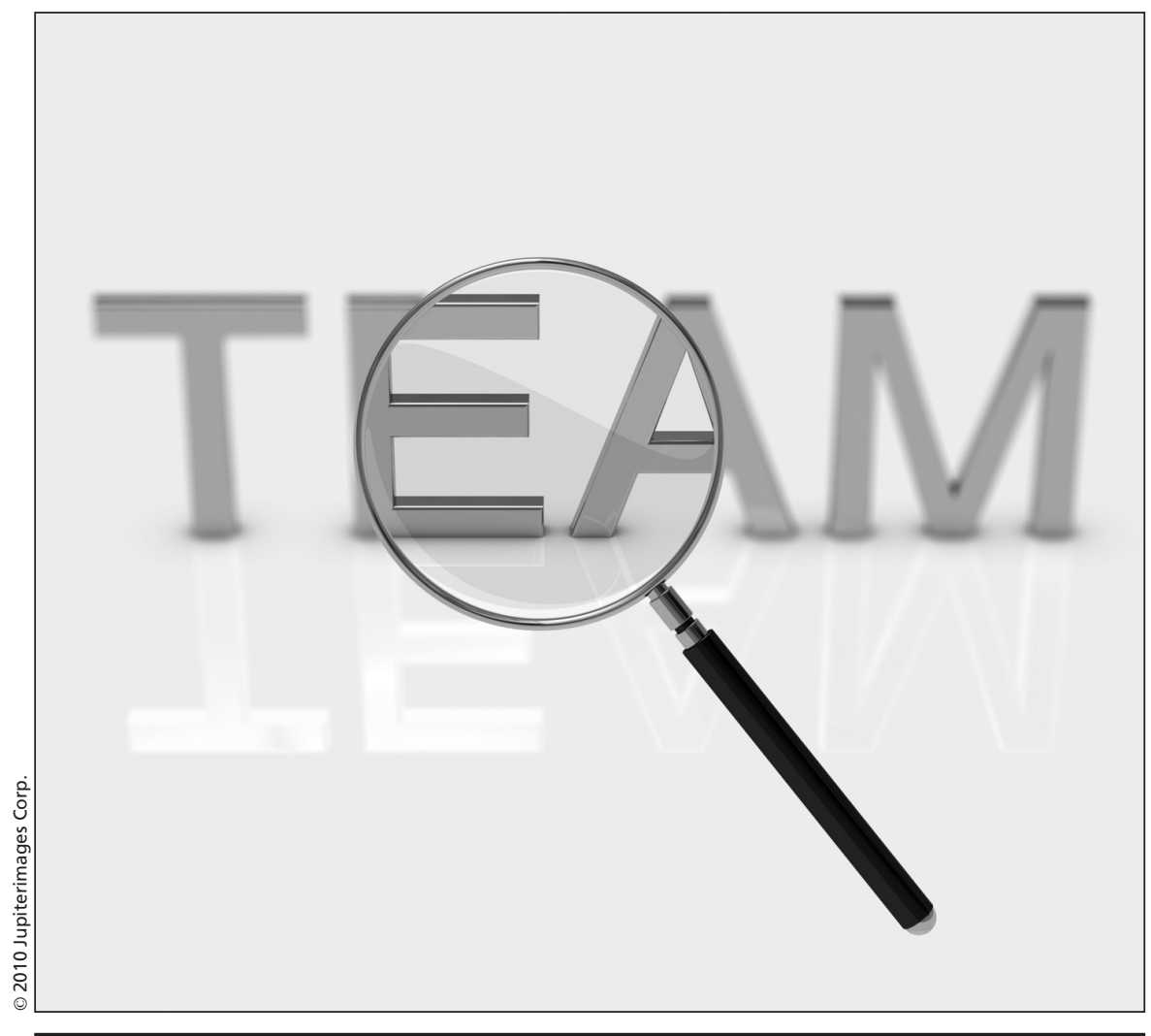

Representatives of some health professions say that many primary health care teams don't stand up under intense scrutiny and that physicians need to be more flexible in encouraging collaborations.

multidisciplinary primary health care teams, less than a third of patients have access to those teams, said Dr. Louise Nasmith, principal of the College of Health Disciplines at the University of British Columbia in Vancouver.

Representatives of professional groups told the summit that physicians need to be much more flexible in encouraging collaborations.

"Most medical professions are having to adapt to boundary changes," said Alba DiCenso, director of the Ontario Training Centre in Health Services and Policy Research and Canadian Health Services Research Foundation/CIHR Chair in Advanced Practice Nursing at McMaster University in Hamilton, Ontario.

DiCenso pointed to the Ontario government's decision to pay incentives to physicians working with nurse practitioners - money the Nurse Practitioners' Association of Ontario argues should be devoted to nurse practitioners, not doctors - as an example of conflict arising from provincial officials' reluctance to include new groups of health care professions in policy consultations.

While "excellent" progress has been made and the number of nurse practitioners in Canada has doubled to 2500 since 2006 and to 1500 in Ontario, DiCenso said nurse practitioners, chiropractors, psychologists, physiotherapists, social workers and personal support workers remain excluded from most policy-setting discussions. In Ontario, "the OMA [Ontario Medical Association] remains the only professional association at the policy table." 
She also argued that medical education must in the future promote interprofessional collaboration. "We need far greater openness to new types of collaborations."

Others, including Joshua Tepper, assistant deputy minister in the Health Human Resources Strategy Division of Ontario's Ministry of Health and LongTerm Care, argued that the move toward interprofessional teamwork is on track. "Do we need to worry about moving from a medical model to an interprofessional model? I think we're doing it."

But others suggested that physicians have disproportionate influence in the development of team-oriented programs. Five of 15 members of Ontario's
Interprofessional Care Strategic Implementation Committee are physicians, and only four of the province's 20 or more regulated health care professions are represented (doctors, nurses, social workers and physiotherapists), said Deborah Kopansky-Giles, an associate professor at the Canadian Memorial Chiropractic College.

Other groups, though, reported huge gains in forging collaborations with physicians.

"We've seen great improvement in access to the system for dieticians," said Paula Brauer, assistant professor in the Department of Family Relations and Applied Nutrition at the University of Guelph in Ontario. Recent data indicate that more than half of Cana- dian physicians have access to dieticians, as compared with a fifth in 2000, she said.

Pharmacists are also slowly becoming more integrated, said Lisa Dolovich, associate professor in the Department of Family Medicine at McMaster. It is a "trend that is peppered across the country."

Collaboration can result in "clinically important differences in patient outcomes," she added, citing her own study which found that working in primary health teams "motivated pharmacists to take on new responsibilities" (Res Social Adm Pharm. 2009;5[4]:319-26). Paul Christopher Webster, Toronto, Ont.

DOI:10.1503/cmaj.109-3163 